\title{
Dental Trauma: Periapical Lesions in Longstanding Trauma Cases
}

\author{
Meera S, Chintu, Priya S, Hameeda K
}

\begin{abstract}
Objective: Aim of the study was to assess the consequences in longstanding trauma cases. Method: 15 Longstanding trauma cases was chosen from two private dental clinics. Result: Periapical lesions were seen in all 15 longstanding trauma cases which were chosen in our study. Interpretation and Conclusion: Trauma cases should be treated immediately with necessary treatment to avoid periapical lesions.
\end{abstract}

Keywords: Trauma, periapical lesion

\section{Introduction}

Dental traumatology is the branch ofdentistry that encompasses the epidemiology, etiology, prevention, assessment, diagnosis and management of trauma. Trauma can be simple or complex its management may be interdisciplinary or multidisciplinary. Tooth fracture may occur when heavy occlusal forces are applied to vulnerable tooth 1. Traumatic injuries of teeth and among most serious dental accidents with anterior teeth mostly affects. Some consequences include misshaping, speech defects, psychological, periapical and social effects. The knowledge of can reduce the suffering cost and time of patient 2. Trauma causes death or necrosis of the pulpal tissue inside the tooth. The process of pulpal necrosis causes inflammation and release of toxins at the apex of the tooth. Periapical lesions are associated with trauma or infection 3. Large periapical lesions are associated with anterior maxialla due to trauma. The lesion could be granuloma, cyst, granular compound of solid, soft tissue with cyst have semi solid surrounded epithelium 4. Periapical granuloma is most prevalent of apical lesion. One of the first author Bhaskar analyse that $48 \%$ of cases was granuloma, $42 \%$ cyst, where other pri radicular is $10 \%$ 5. Periapical cyst also termed radicular or dental cyst is most common odontogenic cyst. Usually the periapical cyst is asymptomatic but a secondary infection causes pain. On radiograph, it appears a radiolucency (dark area) around the apex of tooth root. Expansion of the cyst causes erosion of the floor of maxillary sinus. Radiographically it is virtually imposed to differentiate granuloma from a cyst6. Organisms found are $31.8 \%$ for Actinomycosis, $22.7 \%$ propionic bacteria, $18.2 \%$ streptococcus, $13.6 \%$ staphylococcus, $4.6 \%$ porphyromonus gingivalis, $4.6 \%$ peptostreptococus mitis, $4.6 \%$ gram negative bacteria 7 . The common sequel of non-vital tooth is internal resorption which makes endodontic treatment complicated one 8 . Studies have reported a success rate of $8 \%$ after endodontic treatment of teeth with periapical lesion 9. Thus the present study was to assess the periapical lesion are found in longstanding trauma cases.

\section{Material and Methods}

15 cases were chosen from two private clinics among those all 15 cases were maxillary anterior trauma cases. The patients were from the age group of $18-32 \mathrm{yrs}$, among which 12 cases were male and 3 female patients. 10 patients were untreated trauma cases and 5 patients were endodontic treated.

The traumatized patients few came with chief complaint of swelling in the palatal region, but some patients came with the chief complaint of discolouration and broken tooth without pain or swelling.

The patients who were root cannal treated came with the complaint of swelling in palatal region reverted back again even after the tooth was treated after trauma.

OPG and IOPAR of the patients were taken in which all cases showed perapical radiolucency suggestive of periapical lesions, in some cases we saw well circumscribed radiolucency and few showed diffuse radiolucency. Radiographs of some cases showed severe bone loss were the prognosis would be poor.

The root cannal treated trauma cases which reverted with swelling were immediately treated with the course of antibiotics to reduce the infection and then after the course the patients were recalled after the antibiotic course the tooth was extracted as it shows severe bone loss after the extraction the palatal flap was elevated and the cycstic lining was removed it was made sure that the bone is clear of cystic lining. The biopsy was sent to histopathology lab.

In cases with radiolucency and minimal bone loss the patients were treated in a different treatment plan. These cases were endodontically treated with post and core build up and crowns are placed.

Depending on the radiographic and clinical findings treatment plan was given.

All the above cases were recalled periodically they were checked clinically and radiographically.

\section{Result}

On a brief study with 15 longstanding trauma cases, the findings showed that all cases were anterior traumatised cases with the age group of 18-32 yrs and male patients were more to prone to trauma then female. Patients who came with swelling and severe bone loss (fig-2, 3) showed poor prognosis whereas patients who showed periapical lesion with minimal bone loss endodontic treatment was

\section{Volume 6 Issue 12, December 2017}




\section{International Journal of Science and Research (IJSR) \\ ISSN (Online): 2319-7064 \\ Index Copernicus Value (2016): 79.57 | Impact Factor (2015): 6.391}

done to reduce the infection (fig-8, 9). So the inference of the study showed that prognosis of the patient depends on severity of bone loss and size of the lesion and the entire longstanding trauma cases showed periapical lesion radiographically either cysts or granuloma.

\section{Discussion}

The treatment option for periapical lesion may range from convenient non surgical root cannal to surgical intervals. The precise mechanisms involved in periapical lesion is not fully understood. Nevertheless, its generally amend if pulp becomes necrotic, its environment become suitable formicroorganis to multiply and relase toxins into the periapical tissue to initiate an inflammatory reaction and leads to the formation of periapical lesion 10. Tollen (1972) proved that the growth of cyst may attributes to the increase hydrostatic pressure which causes additional osteoclastic activity 11. Calisken stated that in $70 \%$ of cases with periapical lesion healing was within 2 yrs of time. Most of the untreated trauma cases present with periapical lesions with periapical radiolucency radiographically. Severity increase if patients are left untreated and longstanding the toxins are realised and environment become suitable for growth which causes periapical lesion. Hence the trauma cases should be treated immediately to prevent periapical lesions and for better prognosis of the traumatized tooth.

\section{Conclusion}

With the brief study we can conclude that all cases taken in our study were longstanding trauma cases which showed preapical lesion radiographically. The rate of prognosis depends on severity of bone loss and clinical findings.

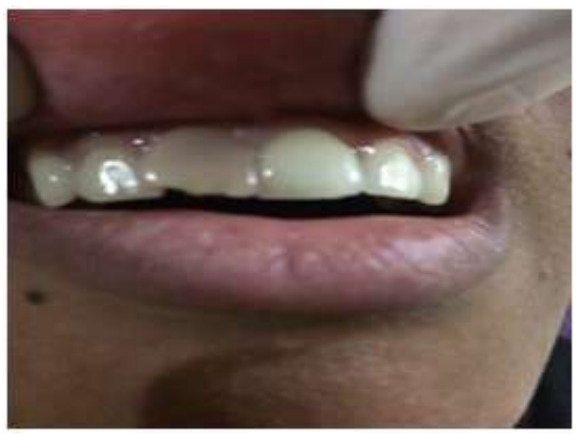

Figure 1: Clinically discoloured tooth after fracture

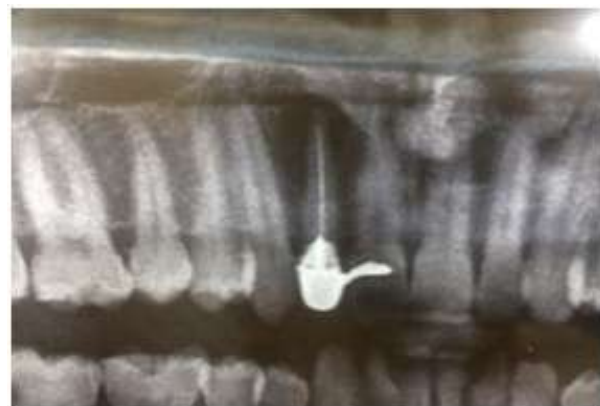

Figure 2: Radiographically periapical lesion in R.C.T

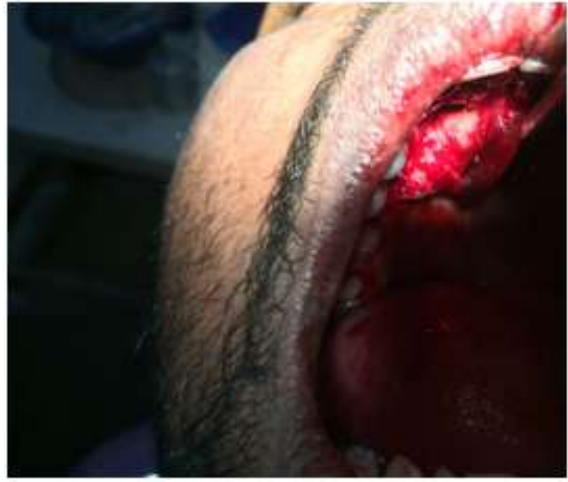

Figure 3: Cystic cavity

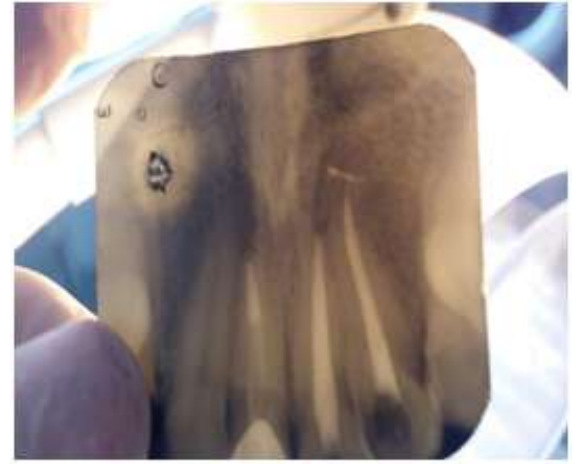

Figure 4: Periapical radiolucency in R.C.T

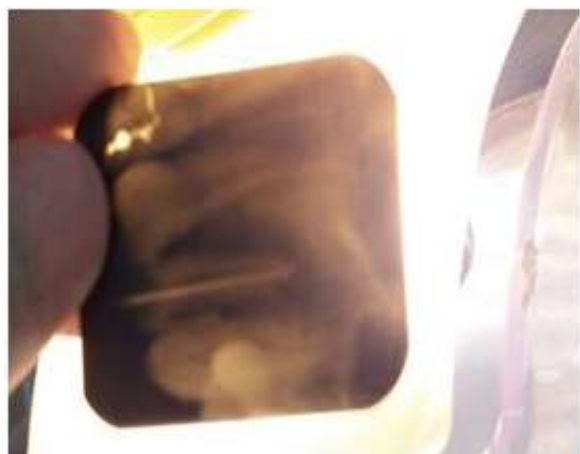

Figure 5: Periapical radiolucency R.C.T

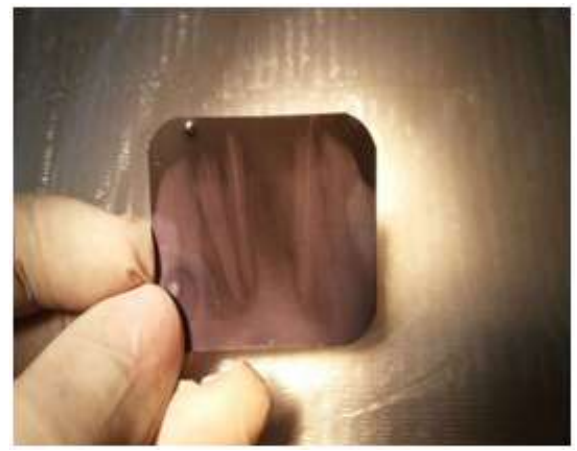

Figure 6: Periapical radiolucency in R.C.T

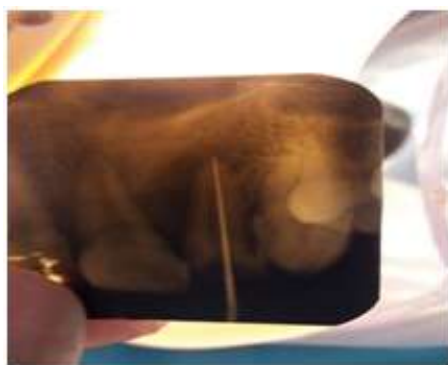

Figure 7: Periapical radiolucency in R.C.T

Volume 6 Issue 12, December 2017

www.ijsr.net

Licensed Under Creative Commons Attribution CC BY 


\section{International Journal of Science and Research (IJSR) \\ ISSN (Online): 2319-7064}

Index Copernicus Value (2016): 79.57 | Impact Factor (2015): 6.391

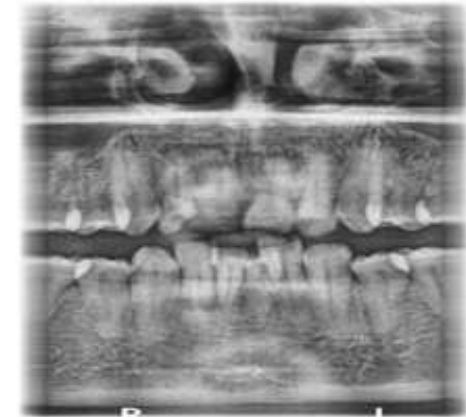

Figure 8: Periapical radiolucency in longstanding case

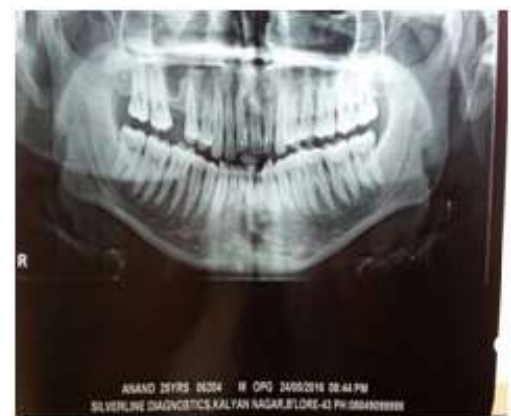

Figure 8: Periapical radiolucency in longstanding

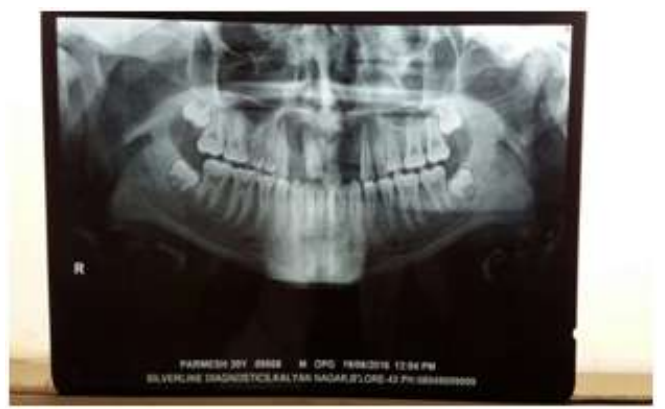

Figure 9: Periapical radiolucency untreated untreated fracture cases fracture cases

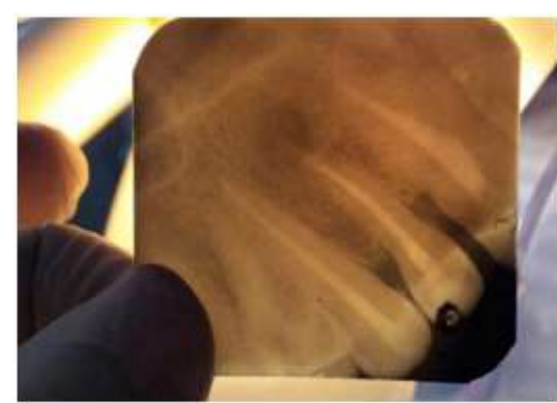

Figure 10: Radiographically periapical lesion in R.C.T

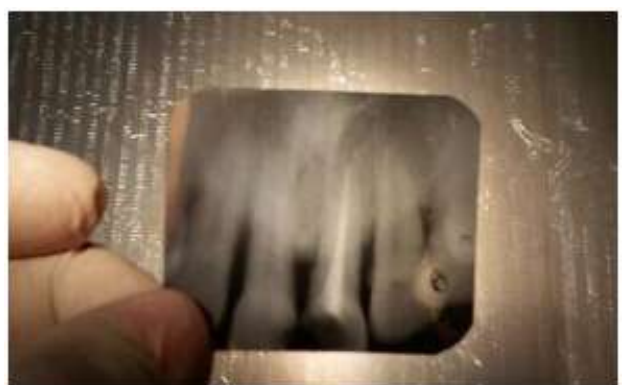

Figure 11: Radiographically periapical lesion in R.C.T

\section{References}

[1] Restorative dentistry $2^{\text {nd }}$ edition 200.

[2] Mohammed.A, Mohammed N, Sara S. Iranian Endodontic Journal. 2006 spring;1(1):37-42.

[3] KAUNO IMPLATOLOGISOS CENTRAS

[4] Nikhil S, Nehah. Int Journal of clinical Pediatrc Restoraton. 2015;8(2):37-42

[5] CASE REPORT INMEDICINE. Volume 2016 Article ID 383098.

[6] Kahn, Michael. Basic Oral and Maxillofacial pathology. 2001 volume 1.

[7] Abou-Rass, Boger G.Int Endod J. 1998 Jan;31(1):39-47.

[8] Anderson JD, Farik B. long standing Caoh as root cannal dressing, increase root fracture. Dental Traumatology. 2002; 18:34-37

[9] Marina I, Ida de At ale. J Conservative Dentistry. 2010 Oct;13(4):240-245.

[10] Kandai AM, Quoud OA. Healing of periapical lesion follow non surgical endo-thesis. Quintessance Int. 1994; 25(2):115-119.

[11] Tollen DA. New concept of Odontogenic cyst. Int J Oral Surgery. 1972;1(1):3-18

Volume 6 Issue 12, December 2017

www.ijsr.net 